Relato de pesquisa 



\section{A sociedade civil e os conflitos na construção dos megaeventos esportivos no Brasil}

Silvia Cristina Franco Amaral, Dirceu Santos Silva, Marcel Ivan dos Santos \& Gabriel Rocha Vargas*

Resumo: O objetivo do artigo foi analisar a atuação e articulação da sociedade civil na resistência contra a remoção forçada das comunidades em localidades próximas às construções de equipamentos para os megaeventos esportivos. Tratou-se de uma pesquisa descritivo-interpretativa realizada em duas etapas: na primeira, coletaram-se dados nos jornais Folha de S. Paulo e O Estado de S. Paulo (Estadão); e, na segunda, no Portal Popular da Copa e das Olimpíadas. Constatou-se que o processo de remoção forçada de comunidades tem ocorrido em diversas cidades sedes dos megaeventos esportivos, atingindo as camadas sociais menos favorecida da população. A sociedade civil tem se organizado pela Articulação Nacional dos Comitês Populares da Copa (Ancop), que reúne as ações dos comitês populares de cada cidade sede, utilizando diferentes formas de ação na luta contra a violação dos direitos. Os repertórios centrais são ocupações de prédios públicos, práticas de protestos, criação de dossiês, abaixo-assinados e postagens de vídeos em redes sociais.

Palavras-chave: megaeventos esportivos; direitos; movimentos sociais; remoção forçada.

\section{Introdução}

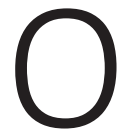

s megaeventos ${ }^{1}$ esportivos, que passaram a integrar a agenda política brasileira, ganharam força no país no ano de 1995, com a solicitação de inscrição ao Comitê Olímpico Internacional (COI) da cidade do Rio de Janeiro como aspirante a sede dos Jogos Olímpicos de 2004. A inscrição foi efetivada em 1996, com apresentação oficial do anteprojeto de candidatura. No entanto, a cidade escolhida foi Atenas. Na candidatura aos Jogos Olímpicos de 2012 (realizada no ano de 2002), mais uma vez o Rio de Janeiro inscreveu-se, e, em 2005, Londres foi anunciada como sede oficial (Benedicto, 2009).

Paralelamente à candidatura dos Jogos Olímpicos, o Rio de Janeiro realizou, em 2000, a candidatura oficial aos Jogos Pan-Americanos de 2007 e, no ano de 2002, a cidade foi anunciada como sede oficial. No ano de 2003, a agenda política dos megaeventos esportivos no Brasil ganhou ainda mais evidência após a Confederação Sul-Americana de Futebol (Conmebol) anunciar que o Brasil seria candidato à sede da Copa do Mundo da Federação Internacional de Futebol (Fifa) de Futebol Masculino de 2014, sendo escolhido oficialmente no ano de 2006 (evento a ser realizado em 12 cidades: São Paulo, Rio de Janeiro, Salvador, Belo Horizonte, Porto Alegre, Brasília, Curitiba, Recife, Fortaleza, Cuiabá, Natal e Manaus). ${ }^{2}$ Em 2007, além

\section{* Silvia Cristina Franco Amaral é doutora em educação física pela Universidade Estadual de Campinas (Unicamp), professora livre-docente da Faculdade de Educação Física da Unicamp.<scfa@ fef.unicamp.br>. Dirceu Santos Silva é doutorando em educação física pela Unicamp, mestre em educação física pela Universidade Federal do Espírito Santo (Ufes).<dirceu_09@ yahoo.com.br>. Marcel Ivan dos Santos é mestre em cultura e turismo pela Universidade Estadual de Santa Cruz (Uesc), mestre em educação física pela Ufes. <marcelivan1@ gmail.com>. Gabriel Rocha Vargas é mestre em educação física pela Unicamp. < gabrielvargas@ gmail.com>.}

1. "Megaeventos são eventos de larga escala cultural (incluindo comerciais e esportivos) que possuem característica dramática, apelo popular massivo e significância internacional. Eles são tipicamente organizados por 
combinações variáveis de governos nacionais e organizações internacionais não governamentais e ainda podem ser caracterizados como importantes elementos nas versões- oficiais da cultura pública" (Roche, 2000: 1 tradução nossa).

2. O Brasil também foi designado como sede da Copa das Confederações Fifa de 2013, que antecede a realização da Copa do Mundo Fifa de Futebol Masculino de 2014.

\section{Além dos três} megaeventos citados, (Jogos Pan-Americanos Rio de 2007, Copa do Mundo Fifa de Futebol Masculino de 2014 e Jogos Olímpicos Rio de 2016), merecem destaque os Jogos Mundiais Militares, realizados no Rio de Janeiro em 2011, e a Copa das Confederações, realizada no Brasil em 2013.

\section{O conceito de} sociedade civil apresentado no presente artigo foi concebido por Cohen e Arato (2001) e compreende as associações sociais, os grupos vizinhos, as redes de ajuda mútua e as estruturas com base nos serviços coletivos. Esse conceito é ideal para abordar a atuação da sociedade civil contra a remoção de comunidades e da realização dos Jogos Pan-Americanos no Rio de Janeiro, a cidade candidatou-se, pela terceira vez, aos Jogos Olímpicos, sendo anunciada, em 2009, como sede oficial do evento a ser realizado em $2016 .^{3}$

A partir do anúncio que o Brasil sediaria os maiores eventos esportivos, iniciou-se uma série de questionamentos e debates nas diferentes esferas públicas brasileiras, bem como no âmbito da sociedade civil, ${ }^{4}$ acerca dos elementos catalisadores de oportunidades das cidades, que podem influenciar nos seus desempenhos econômicos, políticos, culturais, sociais e históricos. A discussão das questões urbanas associadas ao esporte, conforme nos indica Schimmel (2013), é recente, sendo que essas reflexões ainda são desconhecidas no campo do estudo urbano. Para este estudo optamos por debater sobre o direito à moradia associado à premência dos megaeventos esportivos.

Os megaeventos esportivos, por um lado, são compreendidos como positivos para a construção de legados sociais, na melhoria da infraestrutura urbana, para a promoção do turismo, melhoria do transporte e dos equipamentos esportivos.

Uma pesquisa intitulada "Brasil a bola da vez", realizada pelo Instituto Brasileiro de Relações com Investidores (2010), cujo

universo foi as organizações e agentes de mercado [...] composto por dois grupos: profissionais de relações com investidores (RIs), que representam suas respectivas organizações ao retratar o papel estratégico do RI como agente catalisador de oportunidades geradas pelos megaeventos esportivos. Organismos investidores em geral, que englobam entidades de previdência privada abertas e fechadas, companhias seguradoras, fundos de private equity e venture capital e outros investidores e intermediários (bancos, corretoras, fundos de investimento e agentes autônomos) (Ibri, 2010: 4).

Tais dados corroboram, em grande parte, as críticas que acusam os megaeventos como eventos a priorizarem o atendimento aos negócios esportivos e à acumulação de capital, embora se possa notar que há expectativas de investimento em infraestrutura urbana. Entretanto, as prioridades não são para obras que atendam à infraestrutura urbana, com distribuição igualitária entre as diferentes regiões brasileiras, sobretudo, aquelas que mais precisariam, pois as maiores oportunidades se concentram nas regiões mais ricas do Brasil. Além disso, em decorrência das obras, estão os problemas associados à remoção forçada de comunidades localizadas nas imediações dos locais de eventos. Aos moldes dos Jogos Pan-americanos Rio de 2007, os projetos para os megaeventos indicam que uma eugenização e higienização ${ }^{5}$ dos espaços (que certamente terão seus valores de troca bastante alavancados após tais eventos), além 
da desapropriação de comerciantes, falta de transparência no planejamento e transferências de espaços públicos para o setor privado.

Na Tabela 1, é possível observar os valores de investimentos na construção ou reforma das arenas para a Copa do Mundo de 2014 e o número de habitantes de cada cidade envolvida. A tabela deixa claro que os recursos financeiros se concentraram na Região Sudeste do país, especialmente nas cidades de São Paulo e Rio de Janeiro. Outras duas cidades sedes se destacam por terem elevado gasto (Natal e Cuiabá) com número menor de habitantes, além da inexistência de clubes expressivos para manter as arenas após a copa, com riscos de se transformarem em "elefantes brancos". Essas obras correspondem às valiosas construções que fazem uso de dinheiro público por meio de empréstimos com o Banco Nacional de Desenvolvimento (BNDES) ou de incentivos fiscais.

Oliveira (2011) demonstra que o crescimento econômico e as oportunidades advindas dos megaeventos enfrentam problemas de diversas ordens. Conclui seu artigo relatando que defesa da habitação, já que proporciona um espaço de experimentação social para o desenvolvimento de novas formas de vida e de relações de cooperação e trabalho. Além disso, é difícil manter a rígida divisão conceitual entre sociedade civil e sociedade política na visão do Estado ampliado de Gramsci, uma vez que implica uma reorientação da política democrática que se afasta do Estado e dirige a sociedade, sem promover a excessiva politização desta. A reorientação transfere o lócus da democratização do Estado pela sociedade e entende a sociedade civil como grupos, associações e espaços públicos (Cohen, Arato, 2001)

5. Eugenização é
um método de
controle social que
pode melhorar
ou empobrecer
qualidade raciais
físicas ou mentais
de futuras gerações,
que pode ser
relacionado à
eugenia nazista
de pureza racial.
O higienismo é
uma tendência da
medicina social que
entendia a prática
da higiene como
forma revolucionária
de atuação na
coletividade,
impregnada
por conceitos
biologicistas. A

5. Eugenização é controle social que pode melhorar

[...] o consenso em torno dos megaeventos como estratégia de crescimento econômico e social emergiu a partir de uma noção difusa de desenvolvimento local acoplada ao planejamento estratégico. Ademais, a experiência internacional revelou que os megaeventos são estratégias de alto risco, mesmo para os países centrais. Para os países periféricos, onde o déficit de serviços públicos é crônico e a infraestrutura é escassa, sobretudo no que tange aos equipamentos esportivos, a empreitada dos megaeventos beira um ato de fé. Embora não existam dúvidas de que a mobilização de poupança pública resulta em crescimento econômico, como estabelece a teoria keynesiana, não existem indicações concretas de que os setores beneficiados pelos megaeventos são aqueles com maior capacidade de alavancar a economia brasileira. Finalmente e mais importante, os relatórios oficiais e a literatura econômica provam que os inves- 
doença de um indivíduo é explicada a partir dos seus agentes biológicos, físicos, naturais e morais, fora do seu contexto social (Soares, 1994).

\section{A Conferência} Nacional do Esporte se configura como espaço de debate, formulação e deliberação das políticas públicas de esporte e lazer no Brasil, realizada em três etapas municipal, estadual e nacional. As duas primeiras etapas da CNE têm como responsabilidade eleger delegados para a etapa nacional. timentos associados aos megaeventos não contribuem para a redução das desigualdades regionais, pois a concentração de gastos nas áreas dinâmicas do país tende a reter os efeitos multiplicadores dentro de suas próprias fronteiras, o contrário do que é esperado quando o aporte é realizado nas regiões menos dinâmicas. A discussão sobre megaeventos não pode ser capturada pelo espírito ufanista que inunda a imprensa, devendo ser substituída pela análise ponderada dos custos e benefícios envolvidos nessa estratégia. A despeito do modismo de ocasião, o país conta com instituições, instrumentos e políticas para o desenvolvimento econômico forjados na história e no debate político (Oliveira, 2011: 272).

A agenda política atual dos megaeventos esportivos no Brasil foi apresentada pelo governo federal, via Ministério do Esporte, na III Conferência Nacional do Esporte (III CNE), ${ }^{6}$ em Brasília, no ano 2010. Durante o evento foi discutido o Plano Decenal de Esporte e Lazer, que consiste em "10 pontos em 10 anos para projetar o Brasil entre os 10 mais", cujo documento foi intitulado "Por um time chamado Brasil!" (Brasil, 2010). A partir daquele momento, o Ministério do Esporte, passou a priorizar o esporte de rendimento em detrimento do esporte educacional e do esporte de participação, na tentativa de desresponsabilizar o Estado da garantia do direito ao lazer, transferindo-o para o mercado (como meta para colocar o Brasil entre "os 10 mais"). A proposta dos megaeventos esportivos no Brasil opõe-se às discussões realizadas na I CNE, em 2004, e II CNE, em 2006, quando o objetivo central era a criação de um Sistema Nacional de Esporte e Lazer, visando o atendimento da população com o esporte concebido como direito social (Brasil, 2004; 2006).

De acordo com Castelan (2010), na I CNE, o objetivo foi de democratização do esporte e lazer, com base em uma gestão participativa, apontando para a construção de um Sistema Nacional do Esporte. Na II CNE, a pauta era de aprofundar uma reflexão avaliativa da implementação do Sistema Nacional de Esporte no Brasil, tendo como marco a criação da Lei de Incentivo ao Esporte. No entanto, apesar de apontar para a democratização do esporte e lazer, foi percebido que as discussões nesses espaços não se desdobraram em ações políticas consistentes do Ministério do Esporte.

A realização da III CNE objetivou o desenvolvimento de uma gestão pública empreendedora, com foco nas características do projeto neoliberal, sendo que a temática da remoção de comunidades próximas da realização dos megaeventos esportivos no Brasil foi ignorada na sua apresentação, apesar de atingir diversas famílias nas cidades sedes. O debate desconsiderou o acúmulo das conferências anteriores, bem como a representatividade e legitimidade da sociedade civil, pois partiu de uma demanda interna do governo federal e não das necessidades da sociedade, sendo imposta de cima para baixo (top-down), não formando um bloco histórico (Gramsci, 2002), uma dialética entre as diferentes partes da sociedade, de modo a conformar a totalidade orgânica. 
A partir destes dados iniciais o presente estudo procurou responder algumas questões importantes:

- Como a sociedade civil tem se articulado e se mobilizado no processo de resistência à remoção forçada de comunidades nas proximidades dos megaeventos esportivos no Brasil?

a Como tem se desenvolvido esses conflitos entre o Estado e a sociedade civil?

O objetivo central foi a análise da atuação e da articulação da sociedade civil na resistência contra a remoção forçada das comunidades que habitam o entorno das grandes construções ou o impacto das reformas dos equipamentos a serem utilizados nos megaeventos esportivos.

\section{Percurso metodológico}

Tratou-se de uma pesquisa descritivo-interpretativa, cujo objetivo era o detalhamento dos significados e das características da remoção forçada de comunidades na construção dos equipamentos para os megaeventos esportivos (Richardson et alii, 1999).

A coleta de dados ocorreu em duas etapas. Na primeira, foram coletados dados em dois jornais, Folha de S. Paulo (Folha Digital) e O Estado de S. Paulo (Acervo Estadão), referentes aos anos de 2009 a 2012, período de fortalecimento da agenda política dos megaeventos no Brasil e início das construções dos equipamentos esportivos. A busca nos bancos de dados dos jornais foi realizada com as palavras-chave: megaeventos esportivos; Pan-Americano Rio 2007; Copa do Mundo Fifa de Futebol Masculino de 2014; Jogos Olímpicos Rio 2016; remoção forçada; e remoção de comunidades. As principais limitações encontradas no trabalho com a fonte de jornais esteve relacionado ao anonimato das notícias publicadas, além da ausência de fontes relacionadas à vinculação dos conteúdos das reportagens. Analisar jornais é um desafio, já que as políticas editoriais podem omitir conflitos não reconhecidos publicamente, além de selecionar agentes privilegiados para escreverem na coluna.

Foram coletadas 30 reportagens para análise na Folha de S. Paulo, entre 2009 e 2012, acerca da temática dos megaeventos esportivos, das quais 7 tinham como discussão central a remoção forçada de comunidades. As outras publicações discutiram: (5) legislação dos megaeventos; (4) transportes; (2) hospedagens; (2) turismo; (2) segurança; (2) construção de equipamentos; (2) corrupção; (2) política; e (2) legados sociais. No Estadão, coletamos 12 reportagens sobre os megaeventos esportivos, das quais apenas 2 trataram a remoção forçada de comunidades, não 
sendo frequentes a divulgação deste tema, como na Folha de S. Paulo. Os assuntos mais presentes no Estadão foram: (5) legislação; (2) segurança; (2) legados sociais; e (1) construção de estádios.

Na segunda etapa, foi finalizado o corpus da pesquisa, com a coleta de dados no website do Portal Popular da Copa e das Olimpíadas, que reúne o conjunto de manifestações da Articulação Nacional dos Comitês Populares da Copa (Ancop). As notícias vinculadas são sistematizadas pela Ancop, que comporta os comitês populares de cada cidade sede dos megaeventos esportivos no Brasil, o que permitiu a inferência dos documentos e notícias publicadas pela sociedade civil, com destaque para o dossiê dos "Megaeventos e violações de direitos humanos no Brasil", que, em 2013, estava em sua 3a edição. Os comitês são articulados com os movimentos sociais de moradia, universidades e sociedade civil, na luta contra as violações de direitos humanos. É importante ressaltar que não houve diferenças significativas entre os conteúdos publicados entre os jornais Folha de S. Paulo e Estadão, ambos apresentaram conteúdos contra a remoção forçada de comunidades próximas as construções dos megaeventos esportivos.

A Folha de S. Paulo teve uma característica peculiar, ao disponibilizar a coluna do jornal para diferentes setores da sociedade, isto é, existem notícias da sociedade política e da sociedade civil, gerando um debate mais democrático, para além dos jornalistas da própria Folha. Em relação ao conteúdo divulgado pelo Portal Popular da Copa, foi visível a militância contra a remoção forçada de comunidades próximas as construções dos megaeventos esportivos. No entanto, a militância da Ancop transcendeu a questão da habitação, lutando contra toda violação de direitos.

Para tabulação e interpretação dos dados, a técnica utilizada foi a análise de conteúdo, por se tratar de técnica adequada para trabalhar com documentos e conteúdos de jornais. Foram três polos cronológicos da análise de conteúdo realizada: a pré-análise, com o objetivo tornar operacionais e sistematizar as ideias iniciais, ler e escolher a documentação; a exploração do material, que correspondeu à fase de aprofundamento na leitura e na análise; e o tratamento dos resultados, a inferência e a interpretação (Bardin, 2009).

\section{Os megaeventos esportivos e seus aspectos sociais}

Sediar um megaevento esportivo requer uma preparação da cidade e do país. No caso específico dos Jogos Olímpicos, são critérios centrais: projeto olímpico, instalações esportivas, proposta de repasse das instalações para população (uso coletivo), segurança, sistema de transporte, estrutura de turismo e de lazer, apoio da sociedade civil, e facilidade de telecomunicações (Bittencourt, 1999). 
Tavares (2005), ao analisar distintas experiências dos Jogos Olímpicos, abordou quem são os "vencedores" e os "perdedores". No grupo dos vencedores destacou-se:

1. O Comitê Olímpico Internacional (COI);

2. Os governos;

3. Os políticos da administração municipal que receberão os megaeventos esportivos (com destaque para o desenvolvimento econômico);

4. Conjunto de empresas da área da indústria da construção;

5. Classes médias e superiores;

6. Os trabalhadores com o aumento de emprego;

7. Patrocinadores internacionais e nacionais; e

8. Redes de televisão.

No grupo dos perdedores, foram citados:

1. A ocorrência de desequilíbrio entre ofertas e demanda;

2. O turismo, quando associado às ameaças terroristas;

3. O aumento de preço e supervalorização durante os Jogos;

4. A construção de novas instalações esportivas como implicadores de efeitos ecológicos não desejáveis; e

5. A realocação de recursos e efeitos ecológicos contidas em um impacto mais amplo que a mudança.

Nos resultados apresentados por Tavares (2005: 75), chama a atenção sua compreensão positiva acerca da valorização imobiliária e "aburguesamento" das áreas, quando o autor pontuou que "este processo se reforça pela venda dos imóveis pelos mais necessitados, uma vez que com o aumento do valor dos imóveis se torna uma chance de fazer dinheiro".

Em uma perspectiva contrária a essa argumentação, Benedicto (2009) concluiu que os movimentos sociais (sobretudo o Comitê Social do Pan, que corresponde a um movimento carioca), denunciaram o desrespeito aos princípios de justiça social, ao propor uma política de remoção forçada de comunidades nas proximidades da realização do Pan-americano Rio de 2007. Destacaram-se as comunidades da Marina da Glória, do Engenhão, do Complexo do Autódromo de Jacarepaguá e da Vila Pan-americana, que tiveram grandes perdas durante o processo de luta e resistência. As comunidades fo- 
ram forçadas a saírem das áreas valorizadas para regiões mais periféricas, não sendo de fato uma oportunidade "para fazer dinheiro".

Na desapropriação feita pelo poder público, a indenização é feita pelo valor venal do imóvel, o que, na maioria das vezes, não corresponde ao valor de mercado do mesmo. O valor venal corresponde a uma estimativa que o poder público realiza sobre o preço de determinados bens. Brondino (1999: 93), ao estudar a acessibilidade das pessoas a lotes urbanos, afirma que "as escrituras na cidade são registradas utilizando-se o valor venal do imóvel fornecido pela prefeitura, que é bastante baixo, comparado ao valor do mercado".

Nos Jogos Pan-Americanos Rio 2007, os legados sociais não foram efetivados e o projeto urbano para o Parque do Flamengo, mais precisamente na Marina da Glória, foi transferido para o setor privado, vetando o acesso das camadas mais baixas da sociedade e reforçando o modelo elitista dos megaeventos esportivos no Brasil. Além disso, as intervenções do poder público não seguiram as leis ambientais, e não buscou a participação da sociedade civil (Mascarenhas \& Borges, 2009).

Souza e Marchi Júnior (2010), ao refletirem sobre a temática do "legado" esportivo, no caso brasileiro, afirmaram que, nos Jogos Pan-americanos Rio 2007, os espaços e equipamentos não foram democratizados após o evento. A construção do Complexo Aquático Maria Lenk e a concentração das intervenções no bairro da Tijuca, região nobre do Rio de Janeiro, vetou o acesso dos estratos sociais mais baixos, contrapondo um dos critérios, para sediar um megaevento, apresentados por Bittencourt (1999), de repasse dos espaços e equipamentos para toda a população.

Vainer (2000) afirma que o planejamento estratégico na cidade do Rio de Janeiro eliminou a perspectiva de democratizar a distribuição de equipamentos coletivos urbanos e regionais, a longo prazo. O modelo de cidade global, ao invés da universalização dos equipamentos e recursos tem vetado o acesso às camadas mais baixas da população. A cidade é compreendida como mercadoria de luxo, destinada a um grupo de

7. Para ler mais sobre a proposta do turismo social no Brasil e no mundo, consultar Caio Luiz de Carvalho e Luiz Gustavo Medeiros Barbosa (Orgs). Discussões e propostas para inovações no turismo: observatório de inovação no turismo. Rio de Janeiro: Senac, 2006. elite de potenciais compradores.

Os Jogos Pan-Americanos Rio 2007 também tiveram como meta o desenvolvimento do setor turístico, como um legado social. No entanto, "[...] o alardeado turismo dos jogos muito pouco contribuiu à economia da cidade, do estado e do país, sobretudo devido às notícias de iminente caos aéreo" no aeroporto de Congonhas em São Paulo (Silva \& Pires, 2006: 11).

Além da ótica do turismo de mercado em detrimento do turismo social, ${ }^{7}$ ficou evidente que o setor da segurança pública tem beneficiado as elites dominantes, o que 
vinha ocorrendo no Brasil, mas reforçado ainda mais em época dos megaeventos, em especial, nos arredores das construções de equipamentos relacionados aos mesmos. Vale ressaltar que o investimento público direcionado à realização dos megaeventos esportivos não é a prioridade da população, beneficiando as elites locais, bem como a Fifa e o COI. Dessa forma, as promessas de legados sociais para toda a população na área de infraestrutura, transporte, segurança, lazer e turismo não são tão abrangentes como afirmado no discurso oficial.

A ótica do mercado e benefícios aos grupos dominantes foi abordada por Vainer (2000), quando destacou que o planejamento estratégico do município do Rio de Janeiro tem legitimado "projetos caros aos grupos dominantes da cidade", com ênfase na competitividade, empreendedorismo e capital internacional. Esse modelo de cidade global tem buscado impor universalmente, como um modelo ideal, com ênfase na cooperação das elites dos países da América Latina, combinada com as agências multilaterais (Bird, Agência Habitat das Nações Unidas), cujo marketing tem como modelo o sucesso de Barcelona. O planejamento estratégico articula três analogias: a cidade como empresa; cidade como mercadoria; e cidade como pátria.

Capel (2010: 2) alerta-nos a respeito de como o "modelo Barcelona" tem influenciado outras sedes:

La realización de los Juegos Olímpicos de Barcelona en 1992 representó un hito significativo ese sentido, tanto por su impacto para la ciudad organizadora como por su repercusión a escala mundial. Las ciudades que le sucedieron tuvieron muy en cuenta el caso de Barcelona 92 para organizar las Olimpiadas de Atlanta (1996), Sydney (2000), Atenas (2004), y Pekín (2008). De manera similar se hizo en los Juegos Olímpicos de Invierno de Salt Lake City (2002) y en los de Turín (2006). La lucha que ha existido en relación con la atribución de los Juegos Olímpicos de 2012 (asignados a Londres), y de 2016 (a Rio de Janeiro), y el sentimiento de frustración de Madrid y otras ciudades que aspiraban a organizarlos, es una buena muestra de las consecuencias positivas que se atribuyen a la celebración de las Olimpiadas. De manera similar sucede con la pugna por los campeonatos del mundo de fútbol y otras competiciones deportivas. La elección de Valencia como ciudad final de la Copa América de navegación 2007, se consideró que situaría a la ciudad en el mundo del turismo, y atraería a un buen número de visitantes. Y la celebración del reciente Campeonato en Sudáfrica ha vuelto a mostrar la trascendencia de estos acontecimientos. [...] Son muchos los efectos positivos. Pero es posible que tengan también consecuencias menos favorables. Es importante revaluar lo que se hace, gestionar bien lo conseguido, no dilapidar la herencia reunida; y plantear la cuestión de si las inversiones hubieran sido más rentables en otras direcciones (por ejemplo, en equipamientos para los ciudadanos). Que después 
de tantos años en los que nos han martilleado en Barcelona con la consigna de "global, global", una exposición organizada a comienzos de 2010 por un prestigioso centro cultural, financiado por la administración pública (el CCCB), nos descubre que hemos de pensar "local, local" es bien significativo, y puede inquietarnos de si no hemos perdido el tiempo, o si quisimos ir demasiado deprisa.

A Folha de S. Paulo (Folha On-line) publicou, em 14 de agosto de 2007, uma reportagem intitulada "Gastos do governo no Pan-2007 serão alvo da PF". A publicação denunciou que o custo final dos Jogos Pan-Americanos Rio 2007 chegou a R\$ 3,7 bilhões, debitados dos cofres públicos (municipal, estadual e federal), quase $800 \%$ a mais que o previsto (Rangel, 2007).

Pode-se afirmar que o principal legado no Brasil com o Pan-Americano de 2007, os Jogos Olímpicos Rio de 2016 e a Copa do Mundo Fifa de Futebol Masculino de 2014 foi a entrada "oficial" do país no circuito internacional, inseridos em um sistema mercadológico de consumo regido pela lei da oferta da sociedade capitalista. O termo "legado social" foi justificado para angariar recursos, criando uma cultura de legados sociais, que pode mascarar ou colocar em segundo plano o problema das desigualdades sociais que a sociedade brasileira tem como característica singular (Souza \& Marchi Junior, 2010).

Nesse contexto, o avanço das estratégias neoliberais, no Brasil, contrapõe-se ao projeto político democratizante dos anos de 1980, que contempla o alargamento da democracia, a ampliação da cidadania e a participação da sociedade civil. Os anos de 1990 foram caracterizados por uma inflexão nas relações entre Estado e sociedade civil, substituindo o confronto aberto por uma atuação mais conjunta. O novo papel desempenhado pelas ONGs e a emergência do chamado terceiro setor, com forte ênfase na filantropia e marginalização dos movimentos sociais, foi crescente, seguindo o mesmo movimento processado em escala global (Dagnino, 2004). Frente a este cenário de institucionalização nacional dos megaeventos esportivos, pesquisamos a remoção forçada de comunidades locais e entornos da realização dos eventos.

\section{Remoção forçada de comunidades nos megaeventos esportivos a partir dos jornais a Folha de S. Paulo e Estadão}

A primeira publicação da Folha de S. Paulo (22 Dez. 2010: 8-9) relacionada à remoção forçada de comunidades foi intitulada "Vizinhos da festa" e foi objeto de uma edição especial. Nesta primeira publicação foi relatada que as reformas e as construções de estádios desalojariam diversos comerciantes em todo o Brasil. No caso de Belo Horizonte já atingira cerca de 300 famílias e 250 comerciantes associados, sendo 150 associados efetivos despejados após a interdição para construção da arena para Copa 
do Mundo. Em Porto Alegre, o secretário extraordinário da Copa do Mundo Fifa, "Ricardo Gothe, estima que a cidade precisará realizar cerca de 4.000 desapropriações", próximas ao estádio do Beira-Rio. Em Fortaleza as remoções podem chegar a 4.000 famílias, com a justificativa que as desapropriações desafogarão o trânsito em torno do estádio Castelão, sendo que a comunidade mais atingida será a da favela do Lagamar, umas das maiores da capital cearense.

As desapropriações e remoções evidenciaram como o Estado brasileiro não tem reconhecido o outro como sujeito de interesses e aspirações, o que corrobora com a discussão realizada por Telles (2001) ao apontar para a ordem excludente da sociedade brasileira, cujo poder é centralizado e os espaços de negociação são escassos. A linguagem do Estado tem se configurado por meio da violência policial, reforçando as representações hierarquizantes e acionando os preconceitos em relação à condição de cor, origem, trabalho, moradia e educação.

Em publicação de 24 de novembro de 2011, intitulada "O país se move", Juca Kfouri (2011: D5) relatou que a sociedade brasileira não está imóvel, enfatizando a atuação do Comitê Popular Rio Copa e Olimpíada, que tem realizado um debate sobre a questão da remoção. Chamou a atenção para a necessidade de divulgação do processo de remoção forçada até chegar ao "blindado" Palácio do Planalto. A reportagem pontuou ainda que têm acontecido

ocupações à força, desapropriações com pagamentos abaixo do valor das moradias, ameaças, tem de tudo sob quase absoluto silêncio da imprensa em geral, mas, menos mal, não das comunidades em particular (Kfouri, 2011: D5).

Na reportagem escrita por Juca Kfouri, ficou visível o campo de força entre os interesses da sociedade civil e da sociedade política. Esse campo de força também foi destaque em notícia publicada em 13 de dezembro de 2011, intitulada "Olimpíadas e Copa vão despejar até 170 mil", quando foi relatado que:

\footnotetext{
A articulação nacional dos comitês populares da copa elaborou um dossiê, divulgado ontem, no qual estima que entre 150 mil e 170 mil pessoas sejam despejadas devido às obras do Mundial e da Olimpíada (Bastos, 2011: C3).
}

O dossiê proposto pelo movimento foi baseado nos relatos das 21 vilas e favelas de 7 das 12 cidades sedes dos megaeventos esportivos no Brasil (Belo Horizonte, Curitiba, Fortaleza, Porto Alegre, Recife, Rio de Janeiro e São Paulo). O documento critica as três esferas de governo por falta de transparência e pelo atendimento às exigências da Fifa e do COI, afirmando que o investimento não condiz com a proposta de legados, 
já que "cerca de R\$ 30 bilhões devem ser investidos em obras nas doze cidades-sedes da copa. Nas olimpíadas, a conta inicial, apresentada em 2009, era de R\$ 28 bilhões" (Bastos, 2011: C3).

Em 23 de dezembro de 2011, a Folha publicou outra reportagem: "A Copa do Mundo Fifa de futebol masculino já tem seus perdedores", de Guilherme Boulos, que apresentou a estimativa de que as remoções forçadas giram em torno de 70 mil famílias, conforme publicado pelo dossiê produzido pela relatora da ONU e urbanista Raquel Rolnik. A reportagem cita ainda o estudo realizado pelo Tribunal de Contas da União (TCU), afirmando que $98,5 \%$ do orçamento dos megaeventos esportivos no Brasil serão financiados com dinheiro público. Se, por um lado, os perdedores são as comunidades, por outro, os vencedores já foram definidos, conforme trecho do jornal:

\footnotetext{
Quem "sorri de orelha a orelha" é o capital imobiliário. As grandes empreiteiras e os especuladores de terra urbana se impõem como os grandes vitoriosos. Levantamento do Creci-SP mostra que em 2010 houve uma valorização de até 187\% de imóveis usados em São Paulo; a rentabilidade dos investimentos imobiliário superou a maior parte das aplicações financeiras. Para esse segmento a Copa é um grande negócio (Boulos, 2011c: A3).
}

Os movimentos sociais, de acordo com Gohn (1991) na garantia do direito à moradia popular, têm lutado contra o capital imobiliário (empreiteiras, construtoras, agentes financeiros, produtores e distribuidores de materiais para construção) mesmo antes do anúncio dos megaeventos. Os representantes da sociedade civil nesse movimento podem ser analisados como sujeitos coletivos, não hierarquizados, que formulam projetos e articulam as reivindicações em organizações estruturadas. O objetivo dessa luta transcende a luta por moradia, envolvendo a democratização dos aparelhos estatais.

Em 15 de abril de 2012, a Folha de S. Paulo publicou a reportagem "Estado futebolístico de execução". O autor Chico Alencar chamou a atenção para a remoção de moradias, com possibilidades de afetar 170 mil pessoas, desrespeitando o princípio de que ninguém pode ser despejado de sua própria casa sem receber outra melhor e próxima. Constatou-se uma crítica à Lei Geral da Copa, já que a mesma fere direitos nacionais para atender um projeto transnacional, assegurando diversos privilégios à Fifa, afrontando até princípios liberais, como o de livre iniciativa. Ademais, não existe transparência, o processo está envolto de grande subserviência, já que

os compromissos do governo com a Fifa, assinados em 2007, seguem cercados de mistério. As informações sobre gastos e etapas das obras, nos portais oficiais, são contraditórias e incompletas (Alencar, 2012: A3). 
Em outra publicação da Folha de S.Paulo, de 27 de abril de 2012, intitulada "Experiência não conta?", Barbara Gancia realiza diversos questionamentos, levando em consideração as experiências da realização da Copa do Mundo de 2010 no continente africano. A notícia destacou, na oportunidade, a urbanista da África do Sul Zahira Asmal, que enfatizou a experiência da Copa do Mundo naquele continente, afirmando que os objetivos de sustentabilidade, melhoria de transporte e moradia não foram alcançados e lançou o seguinte questionamento para o Brasil: "a sociedade civil vai se mobilizar ou serão as construtoras de sempre (e as de ocasião) a dar as cartas?".

Citou o modelo de Londres, como solução para solucionar os problemas de moradia, quando:

[...] derrubou barreiras e integrou a cidade, há uma lei que obriga cada área nobre a acolher $x$ metros de "public housing", de "moradias públicas". É um passo ousado, que talvez nem caiba discutir aqui. Já imaginou alguns andares das torres em cima do shopping Cidade Jardim serem cedidos à Companhia de Desenvolvimento Habitacional e Urbano (CDHU)? (Gancia, 2012: C2).

De acordo com o Centre on Housing Rights and Evictions (Cohre, 2007), sediar um megaevento esportivo é uma poderosa oportunidade de envolvimento de diversos setores da sociedade. No entanto, os impactos negativos também podem estar presentes, com destaque para o direito à moradia, que tem como corresponsáveis os três níveis de governos, as comissões organizadoras, os patrocinadores, os participantes de construção de empresas, os investidores e os espectadores. Destacam-se os exemplos de Seul e Atlanta, que terceirizaram o processo de despejo para entidades privadas, já que essas entidades estão menos preocupadas em incluir as camadas sociais mais baixas da população no planejamento. Os megaeventos devem buscar o aumento de investimento e desenvolvimento de uma cidade sede, de forma que tenha impactos positivos na questão habitacional, sendo que um dos fatores com potencial para minimizar os impactos negativos de habitação é a inclusão de representantes da sociedade civil no seu planejamento.

As organizações da sociedade civil têm um papel importante na mobilização para as transformações sociais, no entanto, de acordo Avritzer e Costa (2004), a sociedade civil é autolimitada, e não deve se tornar uma estrutura formalizada e nem atuar como estrutura burocrática estatal, já que a sociedade civil não deve ocupar funções que cabem ao Estado. A sociedade civil deve atuar como conjunto de organizações sociais e políticas responsáveis pela elaboração e transmissão de ideologias, cuja função é elevar a massa da população a um determinado nível moral e cultural, no sentido de que essa lute pelo direito à moradia. 
Na última publicação analisada da Folha de S. Paulo, em 4 de outubro de 2012, intitulada "Moradores de 'favela esquecida' no Rio vivem entre escombros e ratos", Fabio Brisolla destacou a remoção forçada de famílias próximas da comunidade do Metrô:

[...] situada a 500m do estádio da final da Copa de 2014, a favela está sendo removida pela prefeitura. Desde outubro de 2010, moradores de 354 casas foram para conjuntos habitacionais [...]. Em quatro anos, a gestão Eduardo Paes (PMDB), candidato à reeleição, removeu 19 mil famílias em 192 comunidades (Brisolla, 2012: C4).

No segundo jornal analisado - Estadão -, foi publicada uma reportagem, em 5 de março de 2010, intitulada "Olimpíada e copa trazem prejuízo social", de autoria de Jamil Chade. O artigo afirma que os megaeventos esportivos têm afetado o direito à moradia de boa parte da população.

A organização de Copas do Mundo e Jogos Olímpicos causou a expulsão de milhares de pessoas de suas casas e, na grande maioria dos casos, teve impacto negativo sobre a situação de moradia para a população. A conclusão é da Organização das Nações Unidas (ONU), que apresenta hoje, em Genebra, seu primeiro relatório completo sobre o impacto de megaeventos esportivos sobre a vida das pessoas nas cidades que os sediam e desfaz o mito de que apenas trazem benefícios à população (Chade, 2010: 82).

Segundo Raquel Rolnik, os benefícios econômicos dos megaeventos não são distribuídos de forma adequada à população. Os legados de infraestrutura nas cidades mascaram as desigualdades sociais, característica central do caso brasileiro, o que ratifica a argumentação proposta por Souza e Marchi Junior (2010).

Além disso, foram relatados exemplos - como o caso dos jogos de Seul, em 1988, que violentamente expulsou $15 \%$ da população e demoliram 48 mil edifícios; nos jogos de Barcelona, 1992, 200 famílias foram despejadas para a construção de novas estradas; nos jogos de Dallas, em 1994, cerca de 300 pessoas foram expulsas de suas residências; em Atlanta, em 1996, foram removidos 15 mil moradores de baixa renda; nos Jogos Olímpicos de Sydney, cerca de 6.000 pessoas foram desalojadas para sua preparação; nos Jogos de Pequim, 2008, ocorreu a remoção de 1,5 milhão de pessoas de suas moradias; na Copa da África do Sul, mais de 20 mil moradores foram desalojados e transferidos para áreas empobrecidas e sem acesso aos serviços básicos. Na cidade do Rio de Janeiro, a relatora acredita que a maior preocupação diz respeito à Vila do Autódromo, que deverá sofrer remoções para as obras do evento (Chade, 2010: 82). 
Em outra reportagem, publicada pelo Estadão, em 15 de março de 2012, intitulada "Publicação sul-africana questiona 'legado social' deixado por megaeventos esportivos". Os autores Sívio Barsetti e Tiago Rogero detalham que os eventos como a Copa do Mundo e os Jogos Olímpicos devem ser examinados com mais realismo e menores expectativas. A opinião é da consultora sul-africana Liepollo Pheko, que ainda questiona a ideia do "legado social" deixado às cidades-sedes e a expectativa das mídias antes dos megaeventos esportivos (Barsetti \& Rogero, 2012).

As expectativas presentes no contexto da copa de 2010, na África do Sul, também estão presentes na mídia impressa no Rio de Janeiro. De acordo com pesquisa realizada por Silva et alii (2011), a mídia impressa brasileira enfatiza os legados em diversos setores como o transporte (bus rapid transit), o emprego, o meio ambiente, o turismo, a educação e a segurança pública, via Programa Nacional de Segurança com Cidadania (Pronasci). Outros setores que também receberão recursos são: a saúde, a construção civil, a transparência política e os negócios relacionados ao empreendedorismo.

O Ministério do Esporte lançou em 2009 três cadernos de legado para os Jogos Olímpicos:

a. caderno de Legado Urbano, que reafirma a revitalização da zona portuária, regeneração das áreas do Maracanã, Engenhão e do Sambódromo, ligando as diversas regiões do Rio com o transporte de massa bus rapid transit (BRTs);

b. caderno de Legado Social, que destaca o programa socioesportivo "Segundo Tempo", como meta para atingir três milhões de jovens beneficiados até 2016; e

c. caderno Brasil - "Este é o País", o qual contém dados do Brasil e do Rio de Janeiro, demonstrando a economia nacional, consolidação da democracia, crescimento científico e tecnológico do país (Brasil, 2009).

Na última publicação analisada do Estadão, em 20 de abril de 2012, "Relatório da ONU critica valor das indenizações no Rio", os autores Sílvio Barsetti e Tiago Rogero destacaram que:

[...] a relatora de Direito à Moradia Adequada do Conselho de Direitos Humanos da ONU, Raquel Rolnik, criticou ontem o valor pago pelo poder público para indenizar as famílias que estão sendo removidas para obras da Copa do Mundo Fifa de Futebol Masculino de 2014 e dos Jogos Olímpicos do Rio, 2016. Ela participou do lançamento do dossiê "Megaeventos e violações dos direitos humanos 
no Rio de Janeiro", elaborado pelo Comitê Popular da Copa e das Olimpíadas (Barsetti \& Rogero, 2012: 51).

Acrescentam vigorosa crítica à indenização no valor de $\mathrm{R} \$ 5$ mil, considera insuficiente para a compra de nova moradia para os desapropriados, enfatizando ainda o caso da Vila Harmonia, rota do sistema de ônibus articulados BRT. Das 65 famílias removidas da vila, o valor indenizatório não ultrapassou a soma de $\mathrm{R} \$ 20$ mil, mesmo se tratando de uma das regiões mais valorizadas do Rio de Janeiro. A relatora da ONU sugere a criação de um protocolo federal em relação à política de remoções (Barsetti \& Rogero, 2012: 51).

Acrescentam-se as reportagens coletadas nos dois jornais, uma matéria do New York Times, de 4 de março de 2012, intitulada "Slum dwellers are defying Brazil's grand design for olympics", de Simon Romero, que mostrou o processo de remoção forçada de comunidades para a realização dos megaeventos no estado do Rio de Janeiro. A reportagem abordou que a luta e resistência tem se utilizado de micromídias para postar suas mensagens em redes sociais, com destaque para o youtube e o twitter. Essa perspectiva de remoção contraria a proposta dos megaeventos esportivos, como expressão máxima de elevação da nação no cenário mundial, sendo símbolos de crescimento econômico e renome internacional (Romero, 2012).

O jornal novaiorquino revelou ainda que o movimento social nas 12 cidades reuniu cerca de 170 mil ativistas que enfrentaram a remoção forçada de comunidades que estão sendo afetadas pelos projetos da Copa do Mundo 2014 e dos Jogos Olímpicos Rio 2016. Os despejos são marcados pela adaptação da lei brasileira, ferindo os princípios constitucionais. Um dos principais desafios da remoção localiza-se na Vila Autódromo, que abre o caminho para o Parque Olímpico, uma vez que a comunidade está resistindo ao despejo (Romero, 2012).

A luta desse movimento enquadra-se na discussão de direito a ter direitos proposta por Dagnino (2004), a partir do momento que a sociedade civil tem se organizado na luta pela redistribuição (igualdade) e reconhecimento (diferença), reivindicando acesso, inclusão, participação e pertencimento. Segundo esta leitura de mundo, o Estado tem de oferecer condições de reconhecimento bem como atender aos interesses expressos pela maior parte dos setores sociais. O processo de luta propõe uma nova sociedade com base na ideia de autonomia e participação ativa da sociedade civil, o que corresponde a uma determinada concepção de mundo. 


\section{A sociedade civil na remoção de comunidades na construção dos megaeventos esportivos brasileiros}

Além dos dois jornais estudados, foram analisadas as notícias publicadas no website das manifestações da Ancop relacionadas à remoção forçada de comunidades nas proximidades das construções dos equipamentos para os megaeventos esportivos.

Foi perceptível que o direito à moradia foi a maior reivindicação desses movimentos sociais no caso desta análise. A habitação é um problema histórico no Brasil e, apesar de sua contemplação como direito na Constituição Federal Brasileira de 1988, o acesso ainda é restrito. Com a realização dos megaeventos esportivos no Brasil - sobretudo os Jogos Olímpicos de 2016 e a Copa do Mundo de 2014 -, houve uma aumento dos conflitos entre o Estado e a sociedade civil, colocando a temática da moradia em evidência. Existe um debate sobre a prioridade dos investimentos já que os megaeventos esportivos estão focados na questão econômica e os seus ganhos são concentrados no setor privado. Além disso, o Brasil não superou o problema da desigualdade social, e apresenta infraestrutura precária nos setores do lazer, do esporte, da saúde, da educação, da segurança, do transporte, dentre outros.

A temática da remoção forçada de comunidades, de acordo com os dados apresentados pela Ancop, via Portal Popular da Copa e das Olimpíadas atinge cerca de:

[...] 150 mil a 170 mil pessoas (os governos se recusam a dar informações precisas). Dentre os inúmeros casos relatados pelos comitês populares da copa destas cidades, emerge um padrão claro e de abrangência nacional. As ações governamentais são, em sua maioria, comandadas pelo poder público municipal com o apoio das instâncias estaduais e, em alguns casos, federais, tendo como objetivo específico a retirada de moradias utilizadas de maneira mansa e pacífica, ininterruptamente, sem oposição do proprietário e por prazo superior a cinco anos (premissas para a usucapião urbana) (Ancop, 2011: 14).

As resistências às remoções forçadas no Brasil estão associadas aos movimentos sociais de moradia, que, de acordo com Gohn (1991), são as organizações mais estruturadas, com propostas claras e representa o que há de mais desenvolvido em termos de participação popular. Tatagiba (2010) acrescenta que o movimento de moradia tem grande poder de convocação, organização e mobilização, são amplos, heterogêneos e complexos. Os movimentos articulam um repertório de ações variadas de manifestações, não se restringido aos canais de participação institucionalizados pelo Estado, como conselhos e conferências. Dessa forma, foi possível perceber que esses movimentos sociais contra a remoção forçada tem como pauta central a questão 
habitacional, sendo que os repertórios centrais são ocupações de prédios públicos, práticas de protestos, criação de dossiês, abaixo-assinados e postagens de vídeos em redes sociais.

Apesar da ampliação de repertórios, foi evidente que os espaços públicos são frágeis (Fraser, 1993), já que a atuação da sociedade civil se configurou exclusivamente na formação de opiniões. Na análise dos dados dos jornais e da Ancop não foram evidenciados espaços públicos fortes, que materializassem a atuação da sociedade civil em decisões ou leis.

Segundo o Dossiê da Ancop, a remoção forçada de comunidades foi justificada pelo governo, como momento propício para incremento da mobilidade urbana e melhoria de qualidade de vida da população. No entanto, esse processo foi marcado pela ausência de um bloco histórico, que prevê o diálogo entre o Estado e a sociedade civil, uma vez que os projetos dos megaeventos esportivos têm atendido as elites dominantes, forçando a remoção com recrutamentos da ação policial, ferindo os direitos à moradia e à informação (Ancop, 2012).

Ao ferir o direito à moradia, não foi considerada a legalidade, que, de acordo com Cohen e Arato (2001), são estruturas de interesse geral, leis e direitos básicos necessários para demarcar a pluralidade, a privacidade e publicidade da sociedade civil. A pluralidade envolve as famílias, os grupos informais e as associações voluntárias, cuja pluralidade e autonomia permitem uma variedade de formas de vida. A publicidade são as instituições de cultura e comunicação; e a privacidade se refere ao domínio de autodesenvolvimento individual e de escolha moral.

Os comitês populares da copa e olimpíadas aos dias 21, 22 e 23 de janeiro de 2012, se reuniram e articularam contra a ação da polícia nas comunidades mais pobres. A comunidade mais afetada foi a do Pinheirinho, se configurando como um dos casos mais trágicos. Cerca de 1.600 famílias, totalizando mais de 6.000 pessoas, que vivem há oito anos na localidade, passaram pelo processo de remoção, por meio da intervenção direta do governo do estado de São Paulo. Essa remoção forçada foi impulsionada pela lógica da privatização e do lucro (Portal, 2012).

Em Fortaleza, Ceará, a luta contra a remoção forçada de comunidades para a construção de um tipo de transporte que facilitaria a mobilidade na cidade, denominada de veículos leves sobre trilhos (VLT), percurso Parangaba/Mucuripe, foi evidente. Segundo o governo federal, o ramal é um conceito de mobilidade urbana para a Copa do Mundo de 2014, fazendo a conexão ferroviária de 12,7km, passando por 22 bairros da capital, com o apoio de oito estações (com sistema de integração com as estações de 
ônibus), que será utilizado por 90 mil passageiros por dia (Brasil, 2012), contrapondo o discurso da não utilidade de tal obra.

O Movimento Nacional de Luta pela Moradia (MNLM) mobilizou-se contra a remoção forçada da comunidade Aldaci Barbosa, e conseguiu a modificação do projeto do VLT, que atingiria diretamente cerca de 250 famílias. O MNLM acrescentou que, apesar da conquista, a luta contra a remoção no estado do Ceará está em andamento, já que existe uma possibilidade de remoção de cerca de 1.700 pessoas, conforme dados fornecidos pelo Metrô de Fortaleza (Metrofor). Com o objetivo de atender as demandas das comunidades atingidas, o movimento lançou o abaixo-assinado contra a remoção da comunidade, em defesa do direito à moradia, do meio ambiente e da transparência (Fortaleza, 2012).

Essa privação de direito na construção dos megaeventos esportivos brasileiros corrobora os termos da discussão apresenta por Telles (2001), ao afirmar que os direitos estão inscritos na dinâmica cultural e simbólica da sociedade. No caso brasileiro, a maior marca é o autoritarismo, as representações hierarquizantes e as desigualdades sociais, não constituindo em uma sociedade da qual os cidadãos compreendam o espaço público justo e igualitário.

Os movimentos sociais brasileiros contra a remoção de comunidades na construção dos equipamentos esportivos para os megaeventos transcendem a esfera da participação institucionalizada a partir do momento que não se restringem aos canais de participação. Enquadra-se dentro dos movimentos sociais com diferentes repertórios de atuações, desde a ocupação de prédios públicos por parte do movimento de moradia, até os protestos, os abaixo-assinados, a criação de dossiês e o intercâmbio de notícias e vídeos em redes sociais.

\section{Considerações finais}

Constatou-se que a atuação da sociedade civil, por meio dos movimentos sociais, na luta contra a remoção forçada de comunidades, tem sido intensificada no Brasil, sobretudo a partir da articulação dos comitês populares da copa e olimpíadas, que estão presentes nas doze cidades sedes da Copa do Mundo e no Rio de Janeiro, sede dos Jogos Olímpicos de 2016, no Brasil. É possível afirmar que estes dois megaeventos têm provocado uma série de remoções forçadas em todo o país, podendo chegar a 17 mil o número de famílias diretamente atingidas, conforme dados apresentados pelos jornais e movimentos sociais. Esse processo de exclusão reforça o modelo hierarquizante e excludente da sociedade brasileira, tendo impactos diretos nos direitos conquistados pela sociedade e garantidos em Constituição. Porém, registre-se que estes direitos, nomeadamente o de moradia, a exemplo de outros, de fato não se 
desdobraram em realidade de forma evidente até hoje, representando uma luta que transcende este momento político analisado.

O projeto político dos megaeventos esportivos tem como beneficiados a Fifa, a Confederação Sul-Americana de Futebol (Conmebol), a Confederação Brasileira de Futebol (CBF), o Comitê Olímpico Internacional (COI), o Comitê Olímpico Brasileiro (COB) e as elites dominantes do país. Foi possível verificar que essas competições não são as prioridades da população e não vieram de uma demanda da sociedade civil. São resultado de "um jogo" daqueles que possuem assento nas decisões políticas brasileiras, tomando este momento como ímpar para projetar o Brasil no cenário internacional, não parecendo importar-se com os possíveis desdobramentos perversos que tais eventos teriam para as questões sociais, como é o caso da moradia.

Por outro lado, foi verificado que a sociedade civil tem se articulado na luta contra a remoção forçada de comunidades, apesar da falta de canais de diálogo entre o Estado e os movimentos sociais. Ou, de canais de diálogo dominados por aqueles que conseguem bancar agilmente seus lobbies no Congresso Nacional, tanto na Câmara como no Senado, bem como garantir por meio de recursos financeiros militância em canais oficiais de participação, como é caso das Conferências de Esporte pelo Brasil afora. A sociedade civil tem se organizado pela Articulação Nacional dos Comitês Populares da Copa (Ancop), que reúne as ações dos comitês populares de cada cidade sede, utilizando diferentes formas de ação na luta contra a violação dos direitos, sendo que os repertórios centrais são ocupações de prédios públicos, práticas de protestos, criação de dossiês, abaixo-assinados e postagens de vídeos em redes sociais.

O texto nos leva a inferir que há necessidade de mais diálogos e mais discussões sobre a temática, o que enfatizaria as características mais democráticas e menos excludentes dos/nos megaeventos esportivos. Além disso, a pesquisa alerta que vivemos um momento político que coloca novamente na ordem do dia a temática do direito à moradia e o direito a ter direitos.

Abstract: The aim of this paper is to analyze the organization of civil society in resistance against the forced removal of communities nearby sport mega-events equipment's constructions. It is a descriptive-interpretative study carried out in two stages: first, data were collected in the newspapers Folha de S. Paulo and O Estado de S. Paulo (Estadão) and afterwards, in Portal Popular da Copa e das Olimpíadas. We found out that the process of forced removal of communities has occurred in several host cities of sport mega-events, impacting even more the underprivileged social strata of the population. Civil society has been organized by the National Coordination of Popular Committees for the Cup (Ancop), which brings together the actions of the popular committees of every host cities, using different approaches to fight the violation of rights. Their main actions are occupation of public buildings, protesting, as well as making dossier petitions and posting videos on social networks.

Keywords: sports mega events; rights; social movements; forced removal. 


\section{Referências}

Alencar, C. Estado futebolístico de execução. Folha de S. Paulo. São Paulo, 15 Abr. 2012.

ASSOCIAÇÃO DOS GEÓGRAFOS BRASILEIROS (AGB). <http://www.agb.org.br/>.

Ancop. Megaeventos e violações de direitos humanos no Brasil. Articulação Nacional dos Comitês Populares da Copa, 2011.

- Megaeventos e violações de direitos humanos no Brasil. 2. ed. Articulação Nacional dos Comitês Populares da Copa, 2012.

Avritzer, L.; CostA, S. Teoria crítica, democracia e esfera pública: concepções e usos na América Latina. Dados: Revista de Ciências Sociais, v. 47, n. 4, Rio de Janeiro, 2004, p.703-728.

BARDIN, L. Análise de conteúdo. 4. ed. Lisboa: Edições 70, 2009.

BARSetti, S; Rogero, T. Publicação sul-africana questiona "legado social deixado por megaeventos esportivos. O Estado de S. Paulo (Estadão), São Paulo, 15 Mar. 2012.

. Relatório da ONU critica valor das indenizações no Rio. O Estado de S. Paulo (Estadão), São Paulo, 20 Abr. 2012.

BAStos, M. Olimpíadas e Copa vão despejar até 170 mil. Folha de S. Paulo, São Paulo, 13 Dez. 2011.

BENEDICTO, D. B. M. Desafiando o coro dos contentes: vozes dissonantes no processo de implementação dos Jogos Pan-Americanos Rio 2007. Esporte e Sociedade, v. 4, n. 10, Niterói, Universidade Federal Fluminense, 2009, p. 1-29.

BitTEnCOURT, A. C. Cidades candidatas versus cidades olímpicas: o processo de eleição, o sucesso, o fracasso, a modelagem e os conceitos de real valor. In: TAVARES, O.; DACOSTA, L. P. (Orgs.). Estudos olímpicos. Rio de Janeiro: Gama Filho, 1999.

Boulos, G. Copa do Mundo Fifa de Futebol Masculino já tem seus perdedores. Folha de S. Paulo, São Paulo, 23 Dez. 2011c.

BRASIL. I Conferência Nacional do Esporte: documento final. Brasília: Ministério do Esporte, 2004.

_- Il Conferência Nacional do Esporte: caderno de resoluções. Brasília: Ministério do Esporte, 2006.

. Caderno legado social. Brasília: Ministério do Esporte 2009. 
_. III Conferência Nacional do Esporte: texto básico. Brasília: Ministério do Esporte, 2010.

— . <http://www.transparencia.gov.br>.

BRISOLLA, F. Moradores de "favela esquecida" no Rio vivem entre escombros e ratos. Folha de S. Paulo, São Paulo, 4 Out. 2012.

Brondino, N. C. M. Estudo da influência da acessibilidade no valor dos lotes urbanos através do uso de redes neurais. 1999. Tese (Doutorado em Engenharia Civil - Trransporte) - Universidade Federal de São Carlos, São Carlos.

CASTELAN, L. P. As conferências nacionais do esporte na configuração da política esportiva e de lazer no governo Lula (2003-2010). 2010. Dissertação (Mestrado em Educação Física) - Universidade Estadual de Campinas (Unicamp), Campinas.

CAPEL, H. Los Juegos Olímpicos, entre el urbanismo, el marketing y los consensos sociales. Biblio 3W. Revista Bibliográfica de Geografía y Ciencias Sociales, v. 15, n. 895 (1), Universidad de Barcelona, 2010.

Cohen, J. L; ARATo, A. Sociedad civil y teoria política. México: Fondo de Cultura Económica, 2001.

COHRE. Mega-events, Olympic Games and housing rights. Centre on housing rights and evictions. Genève: Cohre, 2007.

CHAdE, J. Olimpíada e Copa trazem prejuízo social. O Estado de S. Paulo (Estadão), São Paulo, 5 Mar. 2010.

DAGNINO, E. Sociedade civil, participação e cidadania: de que estamos falando? In: Mato, D. (Org.). Políticas de ciudadanía y sociedad civil en tiempos de globalización. Caracas: FaCes/Universidad de Venezuela, 2004, p. 95-111

FORTALEZA. Metrô de Fortaleza. <www.metrofor.ce.gov.br/>.

FRASER, N. Repensar el ámbito público: una contribución a la crítica de la democracia realmente existente. Debate Feminista, v. 7, México, 1993, p. 23-58.

GAnciA, B. Experiência não conta? Folha de S. Paulo, São Paulo, 27 Abr. 2012.

GoHN, M. G. Movimentos sociais e lutas pela moradia. São Paulo: Loyola, 1991.

Gramscl, A. Cadernos do cárcere. v. 3. Rio de Janeiro: Civilização Brasileira, 2002.

INSTITUTO BRASILEIRO DE RELAÇÕES COM INVESTIDORES (IBRI). Brasil a bola da vez. Negócios e investimentos a caminho dos megaeventos esportivos. São Paulo, Ibri, 2010. 
Kfourı, J. O país se move. Folha de S. Paulo, São Paulo, 24 Nov. 2011.

MASCARENHAS, G; BORGES, F. C. Entre o empreendedorismo urbano e a gestão democrática da cidade: dilemas e impactos do Pan-2007 na Marina da Glória. Esporte e Sociedade, v. 4, Niterói, Universidade Federal Fluminense, 2008, p. 1-26.

Oliveira, A. A economia dos megaeventos. Revista Paranaense de Desenvolvimento, v. 120, Curitiba, Instituto Paranaense de Desenvolvimento Econômico e Social (Ipardes), 2011, p. 257-275.

PORTAL POPULAR DA COPA E DAS OlímPIADAS. <http://www.portalpopulardacopa.org.br>.

RANGeL, S. Gastos do governo no Pan-2007 serão alvo da PF. Folha de S. Paulo (On-line), São Paulo, 14 Ago. 2007. <http://www1.folha.uol.com.br>.

Richardson, R. J. et alii. Pesquisa social: métodos e técnicas. São Paulo: Atlas, 1999.

ROCHE, M. Mega-events and modernity: Olympics and expos in the growth of global culture. New York: Routledge, 2000.

Romero, S. Slum dwellers are defying Brazil's grand design for Olympics. Times, New York, 4 Mar. 2012.

SCHIMMEL, K. Os grandes eventos esportivos: desafios e perspectivas. Belo Horizonte; Campinas: Casa da Educação Física; Unicamp, 2013.

SOARES, C. L. Educação física: raízes europeias e Brasil. v. 1. Campinas: Editora Autores Associados, 1994.

SOUZA, J.; MARCHI JÚNIOR, W. Os "legados" dos megaeventos esportivos no Brasil: algumas notas e reflexões. Motrivivência, v. 34, Florianópolis, Universidade Federal de Santa Catarina (UFSC) 2010, p. 245-255.

SILVA, C. A. F. et alii. Expectativas da mídia sobre o legado das olimpíadas de 2016 : racionalidade instrumental e substantiva. Revista Brasileira de Ciências do Esporte, v. 33, Curitiba, Colégio Brasileiro de Ciências do Esporte, 2011, p. 939-957.

Silva, M. R; PIRES, G. L. Do Pan Rio/2007 à Copa 2014 no Brasil. Que Brasil? E para qual Brasil? Motrivivência, v. 27, Florianópolis, Universidade Federal de Santa Catarina (UFSC) 2006, p. 9-17.

TATAGIBA, L. Desafios da relação entre movimentos sociais e instituições políticas. O caso do movimento de moradia da cidade de São Paulo. Colômbia Internacional, v. 71, Bogotá, Departamento de Ciencia Política de la Universidad de los Andes, 2010. 
TAVARES, O. Quem são os vencedores e os perdedores dos Jogos Olímpicos? Pensar a Prática, v. 8, n. 1, Goiânia, Universidade Federal de Goiás, 2005, p. 48-55.

TelLes, V. S. Os sentidos da destituição. In: Telles, V. S. Cidadania e pobreza. São Paulo: Editora 34, 2001.

VAINER, C. Os liberais também fazem planejamento urbano? In: ARANTES, O.; VAINER, C.; MARICATO, E. A cidade do pensamento único: desmanchando consensos. Petrópolis: Vozes, 2000. 